\title{
Repensando a Sociologia da Educação no Brasil: ações afirmativas e teorias do sul ${ }^{1}$
} Rethinking the Sociology of Education in Brazil: Affirmative actions and theories of the south

\author{
Repensando la Sociología de la Educación en Brasil: acciones afirmativas \\ y teorías del Sur
}

Amurabi Oliveira ${ }^{2}$

\section{Resumo}

Nos últimos anos tem havido um crescente debate sobre as chamadas «teorias do sul», que tornaram visível a necessidade de buscar novas contribuições teóricas para pensar sobre as realidades sociais do «sul global», e isso foi percebido em vários campos da Sociologia, o que inclui a Sociologia da Educação. Neste artigo, pretendo realizar um debate teórico sobre o caráter eurocêntrico da Sociologia da Educação no Brasil desde sua gênese, e os limites das teorias sociológicas «do norte» na explicação das realidades educacionais «do sul». Isso não é apenas para indicar a necessidade de desenvolvimento de novas contribuições teóricas da perspectiva do «sul», mas também para reconhecer como devemos repensar as teorias «do norte», reformulando-as em outros contextos sociais. Tomarei como um fio do meu debate a questão da ação racial afirmativa no ensino superior no Brasil.

\section{Palavras chaves}

Sociologia da educação, teorias do sul, ações afirmativas, ensino superior.

\section{Abstract}

In recent years there has been a growing debate on the so-called «theories of the South», which has made visible the need to seek new theoretical contributions to think about the social realities of the «Global South», and this has been perceived in several fields of Sociology, what includes the Sociology of Education. In this paper I intend to hold a theoretical debate on the Eurocentric character of the Sociology of Education in Brazil since its genesis,and limits of «northern» sociological theories in explaining the «southern» educational realities. This is not only to indicate the need for development of new theoretical contributions from the perspective of «southern», but also to recognize how we need to rethink «northern» theories, reframing them in other social contexts. I will take as a thread of my debate the question of racial affirmative action in higher education in Brazil.

\section{Key words}

Sociology of education, theories of the south, affirmative actions, higher education.

\section{Resumen}

En los últimos años ha habido un creciente debate sobre las llamadas «teorías del sun», que se ha hecho visible la necesidad de buscar nuevas contribuciones teóricas para pensar acerca de las realidades sociales del «sur global», y esto se ha percibido en varios campos de la Sociología, lo que incluye la Sociología de la Educación. En este trabajo intento realizar un debate teórico sobre el carácter eurocéntrico de la Sociología de la Educación en Brasil desde su génesis y los límites de las teorías sociológicas «del norte» para explicar las realidades educativas «del sun». Esto no es sólo para indicar la necesidad del desarrollo de nuevos aportes teóricos desde la perspectiva del «sun», sino también para reconocer cómo tenemos que repensar las teorías del «norte», reformulándolas en otros contextos sociales. Tomaré como hilo de mi debate la cuestión de la acción afirmativa racial en la educación superior en Brasil..

\section{Palabras clave}

Sociología de la Educación, teorías del sur, acciones afirmativas, enseñanza superior.

\footnotetext{
1 Uma versão preliminar deste trabalho foi apresentado durante o III Iternational Sociological Association Forum of Sociology, realizado em 2016 na cidade de Viena, Áustria.

2 Amurabi Oliveira: amurabi_cs@hotmail.com, Universidade Federal de Santa Catarina.
} 


\section{Introdução}

Ainda que se possa concordar que a educação é um objeto relevante da reflexão sociológica desde seus primórdios, como atesta o legado de Émile Durkheim (1858-1917), é inegável que o campo próprio da Sociologia da Educação passa a se constituir e se solidificar enquanto um campo com escopo próprio a partir da segunda metade do século XX, neste sentido, as grandes pesquisas promovidas nos anos de 1960 e 1970, tais como a pesquisa longitudinal do I.N.E.D. ${ }^{3}$ e do «relatório Coleman», são fundamentais para a consolidação desta área.

É a partir das guinadas vivenciadas neste período que a questão da desigualdade de oportunidade, ou mais especificamente, a relação entre sistemas de ensino e desigualdades sociais, torna-se o grande tema da Sociologia da Educação. Esta perspectiva ainda que forjada a partir de realidades empíricas bastante delimitadas, tais como França, Estados Unidos e Reino Unido, em algum grau torna-se hegemônica na Sociologia da Educação como um todo, mesmo em outras realidades sociais. Como nos indica Forquin (1995: 21):

Nem toda a sociologia da educação se reduz ao estuda das desigualdades de acesso à educação entre os grupos sociais e nem tudo o que se escreve sobre a questão da «desigualdade de oportunidades» tem a ver, forçosamente, com a sociologia (aqui, vamos falar somente da educação escolar e universitária) segundo os grupos sociais, seus mecanismos geradores, seus efeitos sobre os processos da estratificação social ocuparam, desde o início dos anos 60, uma posição essencial, para não dizerer dominante, na pesquisa sociológica consagrada à educaşão.

Em países periféricos este cenário se torna ainda mais evidente, de modo que no Brasil, caso particular do qual eu parto, a questão da relação entre educação e desigualdades sociais é central no campo da Sociologia ao menos desde a publicação do Manifesto dos Pioneiros da Educação Nova de $1932^{4}$.

O que se pode perceber, ao menos dentro de uma análise crítica a partir da geopolítica do conhecimento, é que a agenda de pesquisa, bem como as tendências teóricas e metodológicas da Sociologia da Educação no mundo seguem, em alguma medida, aquilo que é pensado desde os países centrais. Obviamente este não é um movimento isolado neste campo, estando presente na Sociologia como um todo, e na produção do conhecimento científico de maneira ainda mais geral.

Proponho-me neste trabalho a realizar uma reflexão crítica do campo da Sociologia da Educação, pensando-a desde a periferia. Indago neste ensaio sobre as possibilidades das teorias forjadas no contexto europeu explicarem a realidade do «sul», e para tanto parto do caso particular da questão das ações afirmativas de caráter racial no ensino superior brasileiro. Problematizo, portanto, os limites das teorias forjadas em outra realidade social para explicar os dilemas educacionais de países que passaram pela experiência colonial.

\section{Eurocentrismo e Sociologia da Educação no Brasil}

A Sociologia da Educação no Brasil em sua gênese e desenvolvimento histórico foi marcada por uma forte influência intelectual europeia, e de forma ainda mais particular pela Sociologia francesa, não à toa o livro Educação e Sociologia de Durkheim fora publicado na França em 1922 e já em 1929 foi publicado no Brasil por meio da tradução de Lourenço Filho (1897-1970), intelectual ligado ao movimento da Escola

3 Sigla de Institut National d'Études Démographiques.

4 Para uma melhor análise dos Pioneiros da Educação Nova no Brasil vide Xavier (2002). 
Nova. Como nos indica Nogueira (2011, p. 66): „Sua receptividade aqui foi enorme: enquanto que, na França, ela só terá uma segunda edição mais de quarenta anos depois (em 1966), no Brasil ela foi sucessivamente reeditada, por muitos e muitos anos».

Porém, a influência desses autores não se dava apenas de forma direta, a publicação em 1940 de Sociologia Educacional de Fernando de Azevedo (1894-1974), considerada a primeira obra de fôlego no âmbito da Sociologia da Educação no Brasil, buscava claramente realizar uma «tradução» das categorias durkheiminianas para a análise da realidade brasileira, o que também se dava de forma articulada com alguma influência do filósofo americano John Dewey (1859-1952).

Tanto Educação e Sociologia quanto Sociologia Educacional encontraram grande feedback nos cursos de formação de professores na primeira metade do século XX no Brasil, sendo obras bastante importantes para a divulgação da Sociologia francesa nos trópicos. Como indica o trabalho de Meucci (2011), entre as décadas de 1920 e 1940 foram produzidos inúmeros manuais de Sociologia, que por sua vez, foram responsáveis pelo processo de rotinização do conhecimento sociológico, amplamente divulgadas nesse período em escolas secundárias e cursos de formação de professores. Nesses manuais, a influência de autores como Comte, Durkheim, Spencer e Le Play era notória, afora a publicação de outros manuais que nada mais eram que traduções de livros europeus.

A criação dos primeiros cursos de Ciências Sociais ${ }^{5}$ no Brasil ainda na década de 1930 consolidou a influência dessa tradição intelectual no Brasil, o que incluiu a vinda de professores estrangeiros para a fundação desses cursos, com destaque para o caso da Universidade de São Paulo (USP). Neste sentido, tal como ocorreu nos demais países da América Latina, as ciências sociais emergiram aqui vinculadas a um forte eurocentrismo em termos teóricos. Isso não significa, contudo, que as ideias formuladas no contexto europeu foram reproduzidas tal e qual no Brasil. Como nos indica Villas Boas (2006), alguns intelectuais brasileiros buscaram, em grande medida, adequar as ideias recebidas ao cenário nacional.

No caso do campo educacional há de se considerar ainda as influências intelectuais recebidas por meio de modelos pedagógicos de ensino e aprendizagem. O próprio debate travado entre católicos e liberais nas primeiras décadas do século XX, especialmente entre as décadas de 1930 e 1960, que compreende o período entre a publicação do Manifesto dos Pioneiros da Educação Nova e a promulgação da primeira Lei de Diretrizes e Bases da Educação de 1961, também era marcado por múltiplas influências de matrizes intelectuais europeias e americanas.

Como os cursos de Ciências Sociais surgiram apenas nos anos de 1930 no Brasil, isso significa dizer que apenas entre as décadas de 1940 e 1950 que houve o surgimento da primeira geração de intelectuais com formação no Brasil nessa área, ainda formada diretamente por esses professores estrangeiros.

Nesse sentido, a famosa «missão francesa» que fundara das Ciências Sociais na USP, que por sua vez produziu um paradigma que se tornou hegemônico em termos nacionais (Motta, 2009), pode ser compreendida como uma peça fundamental processo de colonialidade do saber ao qual se refere Quijano (2005). Não se busca com isso negar a relevância que a incorporação de tais paradigmas teóricos teve para o processo de consolidação das Ciências Sociais no Brasil, mas sim de problematizar quais implicações decorrentes deste processo.

\footnotetext{
5 Importante indicar que no Brasil desenvolveu-se no campo acadêmico ao longo do século XX uma concepção mais estreita de ciências sociais que aquela predominante nos demais países de língua portuguesa e espanhola, pois, ainda que em diálogo com a história, a economia etc., no Brasil a graduação em ciências sociais significa predominantemente uma formação em antropologia, ciência política e sociologia. Desse modo, apenas de forma pontual há cursos de graduação autônomos de antropologia, ciência política e sociologia no Brasil, concentrando-se em nível de graduação tais formações nos cursos de ciências sociais, havendo uma maior especialização a nível de mestrado e doutorado, especialmente a partir da década de 1970.
} 
Devemos atentar ainda para os processos que ocorreram no campo do Ensino Superior e seus desdobramentos no desenho institucional da Sociologia da Educação no Brasil, na segunda metade do século XX temos dois fenômenos que de formas distintas foram decisivos nesse processo. O primeiro foi a criação do Centro Brasileiro de Pesquisas Educacionais (CBPE), fundado por Anísio Teixeira (1900-1971), que almejava produzir uma Policy Science aplicada ao campo da Educação, agregando diversos pesquisadores das Ciências Sociais cujas atividades deveriam se voltar para a investigação social, tendo por finalidade última a formulação de políticas públicas em educação (Silva, 2002), já o segundo foi o advento das Faculdades de Educação com a Reforma Universitária de 1968, que teve um peso significativo para a produção de um distanciamento por parte dos sociólogos brasileiros do debate educacional (Cunha, 1992).

Há de se considerar, portanto, que apesar das tentativas pontuais, a educação tornou-se um tema periférico dentro da Sociologia brasileira, cenário este que ainda perdura, pois apesar do incremento da produção nessa seara (Neves, 2002; Martins y Weber 2010; Oliveira, 2013), ainda é bastante reduzido o número de Sociólogos atuando em Departamentos e Programas de Pós-Graduação em Ciências Sociais/Sociologia, dedicados a esta temática (Oliveira y Silva, 2016).

Volto a destacar aqui a influência do pensamento francês nesse campo disperso, tendo em vista que durante o processo de formação das pós-graduações no Brasil, entre os anos 60 e 80, um considerável contingente de pesquisadores fora financiado para realizar seus estudos doutorais no exterior, sendo a França um dos principais centros receptores. Beillerot (1993), aponta que os brasileiros representaram o maior contingente em número de doutorandos estrangeiros na área de Ciências da Educação na França entre as décadas de 1970 e 1980, e do mesmo modo. Ainda segundo Nogueira (2011), a França permaneceu como principal destino de formação doutoral no exterior de brasileiros entre as décadas de 1980 e 1990, porém o impacto dessa formação vai para além dos efeitos mais imediatos, uma vez que vários destes pesquisadores, na volta ao Brasil, passaram a desempenhar cargos ou funções de grande relevância no meio educacional.

A Sociologia da Educação no Brasil, portanto, só pode ser plenamente compreendida em meio às complexas relações de saber, poder e colonialismo nas quais está inserida. A vinda de intelectuais franceses para a fundação das Ciências Sociais brasileiras, e a ida de pesquisadores brasileiros para a França e outros países para realizarem sua formação intelectual indicam uma relação hierárquica, na qual se reafirma o lugar que cada um dos países possui na produção do saber, especialmente no que tange às ciências sociais. Todavia, essa relação deve ser problematizada ante algumas questões que tangenciam o campo científico de forma mais ampla, tais como:

Da constituição histórica das disciplinas cientificas que se produz na academia ocidental interessa destacar dois assuntos fundacionais e essenciais. Em primeiro lugar está a suposição da existência de um metarrelato universal que leva a todas as culturas e a todos os povos do primitivo e tradicional até o moderno. A sociedade industrial liberal é a expressão mais avançada desse processo histórico, e por essa razão define o modelo que define a sociedade moderna. A sociedade liberal, como norma universal, assinala o único futuro possivel de todas as outras culturas e povos. Aqueles que não conseguirem incorporar-se a esta marcha inexorável da história estão destinados a desaparecer. Em segundo lugar, e precisamente pelo caráter universal da experiência histórica europeia, as formas do conbecimento desenvolvidas para a compreensão dessa sociedade se converteram nas únicas formas válidas, objetivas e universais de conbecimento. As categorias, conceitos e perspectivas (economia, Estado, sociedade civil, mercado, classes, etc.) se convertem, assim, não apenas em categorias universais para a análise de qualquer realidade, mas também em proposições normativas que definem o dever ser para todos os povos do planeta. Estes conhecimentos convertem-se, assim, nos padrões a partir dos quais se podem analisar 
e detectar as carências, os atrasos, os freios e impactos perversos que se dão como produto do primitivo ou o tradicional em todas as outras sociedades.

Esta é uma construção eurocêntrica, que pensa e organiza a totalidade do tempo e do espaço para toda a bumanidade do ponto de vista de sua própria experiência, colocando sua especificidade históico-cultural como padrão de referência superior e universal. Mas é ainda mais que isso. Este metarrelato da modernidade é um dispositivo de conhecimento colonial e imperial em que se articula essa totalidade de povos, tempo e espaço como parte da organização colonial/ imperial do mundo. (Lander, 2005: 13).

A universalização da experiência europeia no campo da Sociologia da Educação possui sérias implicações, especialmente por se tratar de um campo desenvolvido de modo fortemente assentado em investigações empíricas, sobretudo no caso daquelas realizadas após os anos de 1960 (Forquin, 1995). Acerca desse hiato, Silke Weber (Oliveira, 2015: 168) pontua a seguinte questão:

\begin{abstract}
Aspecto que parece pouco discutido, entretanto são as diferentes condições educacionais na França e no Brasil, decorrentes, em grande parte, do entendimento quanto ao lugar atribuido à educação formal: para os franceses, ela está relacionada à construção do ideário republicano. Ou seja, persiste a crença de que a escola é uma instituição a ser salvaguardada, apoiada e melhorada porque é reconhecida como instância que propicia o acesso de forma sistemática, embora diferenciada, ao patrimônio cultural, tecnológico e de conhecimento disponivel sobre o homem e a natureza. No Brasil, ao contrário, a generalização da educação pública se deu somente a partir dos anos 1960, em resposta a pressões decorrentes dos processos de industrialização e de urbanização iniciado no Centro-Sul, no inicio do século XX. A sua concretização inicialmente em alguns estados e municípios, foi materializada mediante recurso a estratégias impensáveis naquele país, tais como o abarrotamento de salas de aula, a diminuição do tempo escolar, com a criação do turno intermediário, recrutamento de professores sem formação adequada ou mesmo sem qualquer formação, tônica que ainda se fazpresente no espaço rural. A consideração explícita dessas diferenças certamente trariam mais rigor nas análises empreendidas sob influência do debate francês.
\end{abstract}

Sendo assim, há de se considerar os diversos locais de produção e enunciação do conhecimento. Como pontua Connell $(2007,2012)$, os limites das teorias produzidas no norte encontram-se, sobretudo, na ausência de referência à experiência colonial. A autora chama ainda a atenção para casos específicos na teoria social contemporânea, como em Pierre Bourdieu, autor que possui uma forte centralidade na Sociologia Brasileira (Costa, 2010). Ainda segundo Connell (2007:44): «Bourdieu’s own project of creating a universally applicable toolkit gave him no reason to search out colonial voices, because it made irrelevant the specific history of the societies throught which the tools are illustrated. Nor did his toolkit require him to address a liberation struggle as a social process».

Nesta direção, apesar de ser um fenômeno mais amplo das Ciências Sociais brasileiras, acredito que há uma particularidade no caso da Sociologia da Educação que deve ser encarada, que diz respeito à forte influência da Sociologia francesa nos seus quadros de referência, como aponta também o trabalho de Costa e Silva (2003). Minha hipótese é que este é um cenário em transformação, marcado sobretudo pelas mudanças que vêm ocorrendo no ensino superior a partir das ações afirmativas.

\title{
3. As Ações Afirmativas e o Impacto na Sociologia da Educação Brasileira
}

Um marco significativo para as mudanças que vêm ocorrendo no ensino superior brasileiro foi a III Conferência Mundial de Combate ao Racismo, Discriminação Racial, Xenofobia e Intolerância Correlata, 
realizada em Durban em setembro de 2001, quando um Comitê Nacional de preparação foi instituído para a Conferência e foram promovidos encontros nacionais para a elaboração de um relatório a ser levado a Durban, neste havia um conjunto de vinte e três propostas destinadas à promoção dos direitos da população negra. Entre elas a «adoção de cotas ou outras medidas afirmativas que promovam o acesso de negros às universidades públicas».

No caso brasileiro, para além de um recorte baseado na classe social, a questão racial sempre foi um ponto nefrálgico para compreendermos as formas de acesso às universidades públicas. Esta questão encontra-se diretamente ligada à situação colonial vivenciada no Brasil, e na América Latina de forma mais ampla, como pondera Quijano (2010), a questão racial foi uma das mais centrais no processo de dominação colonial. Entretanto, como nos chama a atenção Mignolo (2005: 37):

\begin{abstract}
Que a etno-racialidade seja o ponto de articulação do imaginário construído no e a partir do circuito comercial do Atlântico, não exclui os aspectos de classes, os quais estavam dados desde o começo nas fases e na transformação pela qual passou a escravidão, em relação a como era conhecida no Mediterrâneo, a partir de 1517, quando se transportaram da Africa os primeiros quinze mil escravos. E tampouco nega os aspectos de gênero sexual e de sexualidade que analisou Tressler recentemente. É que a etno-racialidade transformou-se na engrenagem da diferença colonial configurada a partir da expulsão dos mouros e dos judeus, dos debates sobre o lugar dos amerindios na economia da cristandade e, por último, pela exploração e silenciamento dos escravos africanos. Foi com e a partir do circuito comercial do Atlântico que a escravidão se tornou sinônimo de negritude.
\end{abstract}

Portanto, não se trata aqui de reconhecer um tipo de desigualdade em detrimento de outras, mas sim de visibilizar como determinadas formas de desigualdades e determinadas experiências sociais só podem ser compreendidas ante a um exame cuidadoso da experiência colonial. Neste sentido, visibiliza-se os limites das teorias forjadas no contexto do «Norte», na medida em que os parâmetros de desigualdade a partir dos quais elas são pensadas em seu processo de elaboração são outros, portanto, acaba por desconsiderar, em grande medidas, as questões próprias da realidade. Para deixar esta questão ainda mais clara é importante considerar que:

No Brasil, a justificativa principal para a ação afirmativa é criar chances de mobilidade para grupos desfavorecidos em uma sociedade de alta desigualdade por meio do ingresso na universidade pública. Isso fica claro pela quase totalidade dos entrevistados brasileiros concordarem com afirmaçōes como «a meta da ação afirmativa é criar oportunidades de mobilidade social para grupos desfavorecidos»; «o papel principal da universidade pública é aceitar estudantes que não podem pagar universidades privadas»; e «a distribuição de estudantes em universidades públicas deve corresponder ao perfil racial e socioeconômico da população». (Silva, 2006: 143).

Este cenário complexifica-se ante aos embates mais amplos que se dão na esfera pública, ao considerar o que comumente se denomina no debate acadêmico brasileiro de «mito da democracia racial», segundo o qual, não haveria barreiras raciais aqui, apenas limites impostos pela condição de classe. De forma homóloga, os argumentos utilizados nas acaloradas discussões em torno das ações afirmativas nas universidades brasileiras em grande medida retomavam questões postas na base desse mito, assentado sobretudo na afirmativa de que somos um país miscigenado.

Se compreendemos que a questão racial, emoldurada pelo projeto colonial aqui implantado, é uma peça fundamental para a compreensão da sociedade brasileira, isso significa, por consequência, que é também peça fundamental na compreensão da dinâmica educacional brasileira. Sendo assim, haveria um 
hiato no processo de transposição de teorias europeias para a compreensão dessa realidade tão marcada pela experiência colonial, ou, nos termos colocados por Rosa (2015: 315-316): «(...) a questão que emerge desta agenda é justamente como produzir teorias sobre o 'mundo', sem que elas sejam sobre um 'mundo'». Porém, isto não deve significar pura e simplesmente o descarte das teorias produzidas no «Norte», mas sim reconhecer seus limites e problematizá-los ante aos contextos locais.

O acesso à educação formal, especialmente ao ensino superior, passa a ter na sociedade brasileira um significado relevante não apenas para a dinâmica de classe, como também para a própria dinâmica das relações raciais.

Para alguns intelectuais que se colocaram contra às ações afirmativas de caráter racial no Brasil como Maggie (2006), essa política não apenas não resolveria a questão da desigualdade racial, como também aprofundaria um processo de racialização da sociedade brasileira. Jesus e Gomes (2014), escreveram sobre essa discussão no Brasil indicando os argumentos utilizados, em muitos casos, novamente se volta a questões como a ausência de diferenças genéticas entre negros e brancos, o que tornaria injustificável as cotas com critérios raciais, assim como, novamente, a ideia da miscigenação e da impossibilidade de se dizer no Brasil quem é branco e quem é negro, porém, tal linha argumentativa desconsidera que a raça existe principalmente enquanto construção social. Volta-se ao argumento que coloca como central a questão da classe em detrimento da dimensão racial, sem considerar aspectos complexos como os apontados por Souza (2005), para o qual a cor não seria algo residual na questão do preconceito racial.

Chamo a atenção, portanto, para o fato de que o debate que tem se desenvolvido no campo da Sociologia da Educação, no que tem tangenciado à questão das ações afirmativas tem demandado uma crítica incisiva ao discurso colonial que tanto hierarquiza o negro na sociedade brasileira, quanto o invisibiliza ante a ideia de miscigenação. Ainda nos dizeres de Jesus e Gomes (2014: 106-107), as ações afirmativas: «(...) darão à sociedade brasileira a possibilidade de construir outros projetos de nação, nos quais as relações étnico-raciais, vistas como estruturais e estruturantes da nossa constituição social, possam ser reconhecidas como componente fundamental para a construção de uma sociedade, democrática, plurirracial e pluriétnica». Outro ponto relevante é indicado por Carvalho (2003: 303), para quem:

A luta pelas cotas para negros no ensino superior brasileiro tem aberto inumeras questões sobre as relações raciais no Brasil que haviam sido silenciadas quase totalmente ao longo de todo o século vinte. Entre tantas questões, revela-se agora o quanto nossa classe acadêmica esteve impune pela exclusão racial que se instalou no nosso meio desde a consolidação das primeiras universidades públicas na década de trinta. É a essa impunidade e a esse silenciamento crônico que dou o nome de racismo acadêmico.

\begin{abstract}
Discutir cotas é repensar e avaliar a função social da universidade pública. Gerida através de verbas do estado, a universidade deveria formar lideranças que representassem a diversidade étnica e racial do país; nada mais claro, portanto, que tivéssemos brancos, negros e indios nos quadros discentes, docente e de pesquisa na nossa academia. Contudo, em um país de $47 \%$ de população de negros (pretos e pardos segundo o IBGE), o contingente de estudantes não passa de $12 \%$ e o de professores, menor que $1 \%$. Vale a pena perguntar-se como foi possivel que um grau de exclusão racial tão escandaloso não tenha suscitado, até agora, praticamente nenhuma discussão ou mesmo incômodo por parte dos acadêmicos brancos brasileiros (entre os quais me incluo), sobretudo na nossa elite de Ciências Humanas e Sociais.
\end{abstract}

Em nosso atual cenário torna-se inviável discutir o ensino superior brasileiro sem considerar as ações afirmativas, portanto, a presença de populações historicamente excluídas no projeto de modernidade oci- 
dental. As ações afirmativas põe em xeque valores considerados básicos na modernidade, sobretudo o de igualdade, que passa a sofrer novas demandas, sendo repensado em novos termos que devem considerar, portanto, as próprias clivagens produzidas pela modernidade. Mais que isso, a partir das ações afirmativas podemos vislumbrar uma possibilidade de crítica incisiva ao projeto de modernidade a partir do qual algumas das categorias clássicas da sociologia são forjadas, ao evidenciar a impossibilidade de pensarmos alguns dos fundamentos básicos da modernidade nas regiões que sofreram a experiência colonial.

A pergunta incitada por Dubet (2008), sobre o que é uma escola justa só poderá ser respondida no contexto do sul global quando considerarmos a problematização sobre o que é justiça e reconhecimento em sociedades que vivenciaram a experiência colonial, marcadas por profundas divisões que incluem a dimensão racial como uma delas. Compreendo, desse modo, que é um desafio para a Sociologia da Educação elaborar conceitos mais plurais de justiça e inclusão, que nos possibilite pensar outras realidades. Esta crítica, postas nestes termos, encara a questão sobre a universalização de categorias particulares, neste caso, a universalização sobre certa concepção singular de justiça escolar.

As novas aproximações teóricas que vem sendo realizadas no campo da Sociologia da Educação no Brasil têm possibilitado o próprio lugar da educação, e da universidade em particular, em países periféricos, pois se a universidade surge em contexto europeu, isso não quer dizer que seu significado não seja dinâmico, como bem pondera Santos (2004: 172): «A reforma da universidade deve dar uma centralidade muito específica às acções contra a discriminação racial».

\section{Considerações Finais}

No decorrer deste breve ensaio buscou-se evidenciar a própria dinamicidade do campo da Sociologia da Educação, o que foi pensado a partir da apreensão da origem e desenvolvimento de um caso particular, que é a Sociologia da Educação produzida no Brasil. Outras pesquisas trazendo uma comparação Sul-Sul também poderiam enriquecer este debate, e de fato tem havido um movimento que apesar de recente tem ganhado fôlego, que é de, justamente, tentar captar de forma mais clara os contornos dos debates da Sociologia da Educação em diferentes latitudes.

Apontou-se para a formação eurocêntrica da Sociologia da Educação brasileira, inserindo-a em meio a questões mais amplas, que inclui a circulação não apenas de autores e categorias de análise, como também de pesquisadores, tanto de europeus que vêm para o Brasil no processo de institucionalização das Ciências Sociais, quanto de brasileiros que vão para a Europa para realizar suas formações doutorais no processo de consolidação da pós-graduação no Brasil.

Por outro lado, destacou-se aqui como que o cenário das ações afirmativas dinamizam o debate educacional, problematizando teorias e categorias analíticas, trazendo a tona os limites das teorias produzidas em outros contextos, bem como a necessidade de repensarmos a Sociologia a partir da realidade do «Sul». Este movimento, contudo, não implica numa rejeição automática e absoluta das teorias produzidas no «Norte», mas sim, num reconhecimento da necessidade de rearranjá-las mediante o reconhecimento de seus limites.

Por fim, acredito também que as ações afirmativas nos permitem realizar uma crítica à modernidade, bem como à universalização de modelos analíticos que tomam o particular como universal. Tais questões são, desta maneira, um desafio não apenas para a Sociologia da Educação em particular, mas para as Ciências Sociais como um todo. 


\section{Referências bibliográficas}

Beillerot, Jacky (1993). Les thèses en sciences de l'éducation. Bilan de vingt années d'une discipline: 1969-1989. Rapport de recherce. Nanterre: Université Paris 10.

Carvalho, José Jorge (2003): “As ações afirmativas como resposta ao racismo acadêmico e seus impactos nas ciências sociais brasileiras". Teoria e Pesquisa, 43, 303-340.

Connel, Raewyn (2012): “A iminente revolução na teoria social”, Revista Brasileira de Ciências Sociais, 27 (80), 9-20. doi.org/10.1590/S0102-69092012000300001

Connel, Raewyn (2007). Southern theory: the global dynamics of knowledge in social science. Lodon: Polity press.

Costa, Marcio y Silva, Graziella Dias (2003): "Amor e desprezo: o velho caso entre sociologia e educação no âmbito do GT-14". Revista Brasileira de Educação, 22, 1010-120. doi.org/10.1590/S141324782003000100010

Costa, Sergio (2010): “Teoria por adição” en Carlos Benedito Martins y Heloisa Helena. Martins (comps.): Horizontes das Ciências Sociais: Sociologia. São Paulo: Anpocs.

Dubet, François (2008). O que é uma escola justa? A escola das oportunidades. São Paulo: Cortez.

Cunha, Luiz Antônio (1992): “A educação na sociologia: um objeto rejeitado?”. Cadernos Cedes, 27, 9-22.

Forquin, Jean Claude (1995): “Sociologia das desigualdades de acesso à educação: principais orientações, principais resultados desde 1965" en Jean-Claude Forquin (comp): Sociologia da Educação: dez anos de pesquisa. Petrópolis: Vozes.

Jesus, Rodrigo Ednilson y Gomes, Nilma Lino (2014): “A ‘Constituição’ da Nação Brasileira em Disputa: o Debate em Torno da (in) Constitucionalidade das Ações Afirmativas”. Revista Tomo, 24, 85-107. doi. org/10.21669/tomo.v0i0.3186

Lander, Edgardo (2005): “Ciências sociais: saberes coloniais e eurocêntricos” en Edgardo Lander (comp.): A colonialidade do saber: eurocentrismo e ciências sociais. Perspectivas latinoamericanas. Colección Sur Sur, CLACSO: Ciudad Autônoma de Buenos Aires.

Maggie, Yvonne (2006): “Uma nova pedagogia racial?”. Revista USP, 68, 112-129.

Martins, Carlos Benedito y Weber, Silke (2010): “Sociologia da educação: democratização e cidadania” en Carlos Benedito Martins y Heloisa Helena. Martins (comps.): Horizontes das Ciências Sociais: Sociologia. São Paulo: Anpocs.

Meucci, Simone (2011). Institucionalização da sociologia no Brasil: primeiros manuais e cursos. São Paulo: Hucitec/ Fapesc.

Mignolo, Walter (2005): “A colonialidade de cabo a rabo: o hemisfério ocidental no horizonte conceitual da modernidade" en Edgardo Lander (comp.): A colonialidade do saber: eurocentrismo e ciências sociais. Perspectivas latinoamericanas. Colección Sur Sur, CLACSO: Ciudad Autônoma de Buenos Aires.

Motta, Roberto (2009): “Élide, Gilberto, Imagismo e Língua de Universidade”. Revista Brasileira de Ciências Sociais, 24(68), 185-206. doi.org/10.1590/S0102-69092009000100011 
Neves, Clarissa Eckert Baeta (2002): "Estudos sociológicos sobre educação no Brasil” en Sergio Miceli (comp.): O que ler na ciência social brasileira 1970-2002: Sociologia. São Paulo: Sumaré.

Nogueira, Maria Alice (2011): “Contribuições francesas para o pensamento educacional e a formação de pesquisadores brasileiros". Cadernos de Estudos Sociais, 26 (1), 63-69.

Oliveira, Amurabi (2015): “A sociologia da educação no Brasil: entrevista com Silke Weber”. Crítica e Sociedade: revista de cultura politica, 5 (1), 158-178.

Oliveira, Amurabi (2013): "Sociologie de l'éducation au Brésil: tendances historiques et contemporaines". Incursions, 8, 75-93.

Oliveira, Amurabi y Silva, Camila (2016): "A sociologia, os sociólogos e a educação no Brasil". Revista Brasileira de Ciências Sociais, 31 (91), 1-15. doi.org/10.17666/319108/2016

Quijano, Anibal (2010). "Colonialidade de poder e classificação social” en Santos, Boaventura de Sousa y Meneses, Maria Paula (Comps.): Epistemologias do Sul. Rio de Janeiro: Cortez.

Quijano, Aníbal (2005): “Colonialidade do poder, eurocentrismo e América Latina” en Edgardo Lander (comp.): A colonialidade do saber: eurocentrismo e ciências sociais. Perspectivas latinoamericanas. Colección Sur Sur, CLACSO: Ciudad Autónoma de Buenos Aires.

Rosa, Marcelo (2015): “A África, o Sul e as ciências sociais brasileiras: descolonização e abertura”. Sociedade e Estado, 30 (2), 313-321. doi.org/10.1590/S0102-699220150002000003

Silva, Graziella Moares Dias (2006): “Ações afirmativas no Brasil e na África do Sul”. Tempo Social, 18 (2), 131-165. doi.org/10.1590/S0103-20702006000200007

Silva, Graziella Moraes Dias (2002). Sociologia da sociologia da educação: caminhos e desafios de uma policy science no Brasil (1920-79). Bragança Paulista: Editora Universidade São Francisco.

Sousa, Boaventura Santos (2004). A Universidade no século XXI. São Paulo: Cortez Editora.

Souza, Jessé (2005): “Classe ou raça? Sobre a desigualdade brasileira”. Lua Nova, 65, 43-69.

Villas Bôas, Glaucia (2006). Mudança Provocada: passado e futuro no pensamento sociológico brasileiro. Rio de Janeiro: Editora FGV.

Xavier, Libânia Nacif (2002). Para Além do campo educacional: um estudo sobre o Manifesto dos Pioneiros da Educação Nova (1932). Bragança Paulista: EDUSF.

\section{Nota biográfica}

Amurabi Oliveira Doutor em Sociologia pela Universidade Federal de Pernambuco (UFPE), Professor do Departamento de Sociologia e Ciência Política da Universidade Federal de Santa Catarina (UFSC), atuante no Programa de Pós-Graduação em Sociologia Política e no Programa de Pós-Graduação em Educação, Pesquisador do CNPq e coordenador do Núcleo de Estudos da Educação e Juventude Contemporâneas (NEJUC). Tem pesquisado principalmente temas relacionados ao Ensino de Sociologia, Formação de Professores, Antropologia e Sociologai da Educação, Pensamento Social brasileiro. Dentre os trabalhos mais recentes publicou: «Uma antropologia fora do lugar? um olhar sobre os antropólogos na educação» (Revista Horizontes Antropológicos, 2017), «Thirty years late: the actuality of Gilberto Freyre 
to Think Brazil» (Revista del Cesla, 2017), «A expansão dos cursos de formação de professores de ciências sociais na região sul do Brasil» (Revista Brasileira de Sociologia, 2016), «A Sociologia e os sociólogos da educação no Brasil» (Revista Brasileira de Ciências Sociais, 2016). 